\title{
Analysis of Genotype by Environment Interaction of Improved Pearl Millet for Grain Yield and Rust Resistance
}

\author{
G. Lubadde ${ }^{1}$, P. Tongoona ${ }^{2}$, J. Derera ${ }^{2} \&$ J. Sibiya ${ }^{2}$ \\ ${ }^{1}$ National Semi-Arid Resources Research Institute, Soroti, Uganda \\ ${ }^{2}$ University of KwaZulu Natal (UKZN), Pietermaritzburg Campus, Scottsville, South Africa \\ Correspondence: G. Lubadde, National Semi-Arid Resources Research Institute, P.O. Box 56, Soroti, Uganda. \\ Tel: 256-772-965-752. E-mail: glubadde@gmail.com
}

Received: August 28, 2016

doi:10.5539/jas.v9n2p188

\author{
Accepted: December 4, 2016 \\ Online Published: January 15, 2017 \\ URL: http://dx.doi.org/10.5539/jas.v9n2p188
}

\begin{abstract}
Pearl millet is grown by inhabitants of the semi-arid zones. Due to the unpredictable climatic conditions the genotype-by-environment interaction (GEI) makes it hard to select genotypes adapted to such conditions. The study objectives therefore were to analyse the patterns of GEI and to identify superior genotypes for grain yield and rust resistance. Seventy six genotypes were planted in four environments in $4 \times 19$ alpha design with two replications. The ANOVA results showed that main effects of environments were significant $(p \leq 0.05)$ for grain yield and highly significant $(\mathrm{p} \leq 0.001)$ for rust resistance while the main effects of the genotypes and their interactions with environments were also important for grain yield and rust severity at 50\% physiological maturity. The GGE biplot analysis revealed that environments associated with more rains received during vegetative phase performed better than those receiving more rains during post-anthesis phase. The winner in the best environment for grain yield was ICMV3771 $\times$ SDMV96053 while Shibe $\times$ CIVT9206 and Shibe $\times$ GGB8735 were the best for rust resistance.
\end{abstract}

Keywords: GGE biplot, grain yield, pearl millet, rust resistance, Uganda

\section{Introduction}

Pearl millet is adapted to environmentally marginalised conditions worldwide (Bashir et al., 2014) and a multipurpose (IFAD, 1999) cereal for people living in semi-arid areas in Uganda (Lubadde et al., 2014). However, on-farm productivity is low partly due to the effect of rust disease. The economical approach to control rust is through resistance breeding (Singh, 1990) and selecting genotypes adapted to low input and drought-prone environments (Vadez et al., 2012). Unfortunately, the potential performance of improved genotypes under marginal conditions is always obscured by the effect of genotype by environment interaction (GEI) (Yan \& Racjan, 2002); leading to selection of genotypes not suitable for particular environments (Cooper \& Delacy, 1994) and subsequently leading to low yield. It is therefore important to assess GEI effect before releasing varieties (Gupta \& Ndoye, 1991; Haussmann et al., 2012). Several methods have been adopted to assess GEI in pearl millet breeding but the GGE-biplot analysis was used in this study because of the ability to graphically better explain the genotype and genotype by environment components of variation and being more efficient in discriminating genotypes and environments (Yan et al., 2007).

\section{Materials and Methods}

\subsection{Experimental Materials and Study Environments}

The experimental materials are shown in Table 1. The seventy six genotypes were evaluated in four pearl millet growing environments in Uganda. They included 60 single cross hybrids developed by crossing six male parents with ten female parents in a North Carolina2 design. The environments were defined as seasons by sites combinations. Environments; E1 was Kitgum site and 2012 second rains; E2 was Kitgum site and 2013 first rains; E3 was Serere site and 2012 second rains while E4 was Serere site and 2013 first rains. 
Table 1. Genotypes evaluated

\begin{tabular}{|c|c|c|c|c|c|c|c|c|c|c|c|}
\hline \multirow{2}{*}{$\begin{array}{l}\text { Female parents } \\
7=\text { Exbornu }\end{array}$} & \multirow{2}{*}{$\begin{array}{l}\text { Male parents } \\
1=\mathrm{ICMV} 3771\end{array}$} & \multicolumn{10}{|c|}{ Crosses } \\
\hline & & $1 \times 7$ & $1 \times 8$ & $1 \times 9$ & $1 \times 10$ & $1 \times 11$ & $1 \times 12$ & $1 \times 13$ & $1 \times 14$ & $1 \times 15$ & $1 \times 16$ \\
\hline $8=$ CIVT9206 & $2=$ Manganara & $2 \times 7$ & $2 \times 8$ & $2 \times 9$ & $2 \times 10$ & $2 \times 11$ & $2 \times 12$ & $2 \times 13$ & $2 \times 14$ & $2 \times 15$ & $2 \times 16$ \\
\hline $9=$ GGB 8735 & $3=$ Okashana 2 & $3 \times 7$ & $3 \times 8$ & $3 \times 9$ & $3 \times 10$ & $3 \times 11$ & $3 \times 12$ & $3 \times 13$ & $3 \times 14$ & $3 \times 15$ & $3 \times 16$ \\
\hline $10=\mathrm{ICMV} 221$ & 4=ITMV8001 & $4 \times 7$ & $4 \times 8$ & $4 \times 9$ & $4 \times 10$ & $4 \times 11$ & $4 \times 12$ & $4 \times 13$ & $4 \times 14$ & $4 \times 15$ & $4 \times 16$ \\
\hline 11=ICMV221 white & 5=SDMV 94001 & $5 \times 7$ & $5 \times 8$ & $5 \times 9$ & $5 \times 10$ & $5 \times 11$ & $5 \times 12$ & $5 \times 13$ & $5 \times 14$ & $5 \times 15$ & $5 \times 16$ \\
\hline $12=$ KatPM1 & $6=$ Shibe & $6 \times 7$ & $6 \times 8$ & $6 \times 9$ & $6 \times 10$ & $6 \times 11$ & $6 \times 12$ & $6 \times 13$ & $6 \times 14$ & $6 \times 15$ & $6 \times 16$ \\
\hline \multicolumn{12}{|l|}{$13=$ Okoa } \\
\hline \multicolumn{12}{|l|}{ 14=SDMV96053 } \\
\hline \multicolumn{12}{|l|}{$15=$ Sosank } \\
\hline $16=$ Okollo & & & & & & & & & & & \\
\hline
\end{tabular}

\subsection{Experimental Sites and Field Layout}

The Kitgum location was $03^{\circ} 13^{\prime} \mathrm{N}, 032^{\circ} 47^{\prime} \mathrm{E}, 969$ m.a.s.l. while Serere location was $01^{\circ} 32^{\prime} \mathrm{N}, 033^{\circ} 27^{\prime} \mathrm{E}, 1140$ m.a.s.l. The genotypes were replicated twice in $4 \times 19$ alpha mating design. The materials were planted in four rows each of $5 \mathrm{~m}$ long and $60 \mathrm{~cm} \times 30 \mathrm{~cm}$ spacing. Fertiliser application was according to Khairwal et al. (2007) and inoculation procedure done according to Thakur et al. (2011).

\subsection{Data Collection and Analysis}

Data was collected on 36 randomly selected plants per plot using the IBPGR and ICRISAT (1993) manual and traits were rust resistance at $50 \%$ physiological maturity $\left(\mathrm{PSM}_{50}\right)$ determined according to Tooley and Grau (1984) and grain yield $\left(\mathrm{kg} \mathrm{ha}^{-1}\right)$. The rust resistance was determined from rust severity data collected from the third leaf from top of the plant. This $\mathrm{PSM}_{50}$ trait was used instead of the area under disease progress curve (AUDPC) since it had a significant effect on grain yield. The trait also seems to be more realistic since it is determined when there is no more change in grain yield. The analysis was done using the Breeding Management System 3.0 (IBP-BMS, 2014) and Genstat (Payne et al., 2012).

\section{Results and Discussion}

\subsection{Combined Analysis of Variance for Assessing GEI and Performance of Environments}

The combined analysis of variance (ANOVA) results (Table 2) indicate the main effects of environments being significant $(\mathrm{p} \leq 0.05)$ for grain yield and highly significant $(\mathrm{p} \leq 0.001)$ for rust resistance at $50 \%$ physiological maturity. The main effects of the genotypes and the interaction effects between genotypes and environments were also significantly $(\mathrm{p} \leq 0.05)$ important for the two traits. Results further show that generally the coefficients of determination $\left(\mathrm{R}^{2}\right)$ estimated from the AMMI model were low for the traits; an indicator that a greater variation was due to the environments. This is corroborated by the rainfall pattern variation observed in each environment (Figure 1). The performance of environments was influenced by the rainfall amount received where the best performing environments in terms of grain yield and rust resistance received lower rainfall amounts. Coincidentally in the best performing environments (E1 and E3), most rainfall was received during the vegetative phase while in the poor performing environments most rainfall was received during the flowering phase. When rainfall is received during flowering, there is disruption of the pollination process since the pearl millet is predominantly outcrossing, with support by wind, a probable reason why the environments performed poorly in terms of grain yield. Heavy rainfall during flowering also causes reduced seed set and poor grain quality (DPP, 2011) in addition to promoting rust and consequently low grain yield. The variation in performance highlights the importance of environments in genotype performance and consequently GEI in trait expression. Rainfall pattern is one of the factors also reported by Gebre (2014) as being a source of variable performance of improved genotypes. The environments being important in genotype performance has also been reported in several pearl millet studies (Ezeaku et al., 2014; Misra et al., 2010; Gupta et al., 2013). The ANOVA adequately identified GEI as a significant source of variation but it is not able to explore the nature (Matus-Cadiz et al., 2003) of the GEI which may mask the true performance of genotypes in certain environments (Crossa, 1990) and thus the need to explore more methods; for which case GGE biplot was adopted. 
Table 2. Combined mean squares for grain yield and rust severity

\begin{tabular}{llll}
\hline \multirow{2}{*}{ Source of variation } & \multirow{2}{*}{ DF } & \multicolumn{2}{c}{ Traits } \\
\cline { 3 - 4 } & & Grain yield $\left(\mathrm{kg} \mathrm{ha}^{-1}\right)$ & Rust severity $(\%)$ \\
\hline Environments & 1 & $3235216.58^{*}$ & $5686.29 * *$ \\
Genotype & 72 & $1269642.59^{*}$ & $55.07^{*}$ \\
Environments*Genotype & 75 & $732365.59^{*}$ & $61.02^{*}$ \\
Error & 447 & 982045.5 & 74.24 \\
$\mathrm{R}^{2}$ & & 0.32 & 0.33 \\
$\% \mathrm{CV}$ & & 5.93 & 14.35 \\
\hline
\end{tabular}

Note. LSD testing done at $\alpha=0.05 ; * *=$ highly significant with $\mathrm{p} \leq 0.001,{ }^{*}=$ significant with $\mathrm{p} \leq 0.05$.

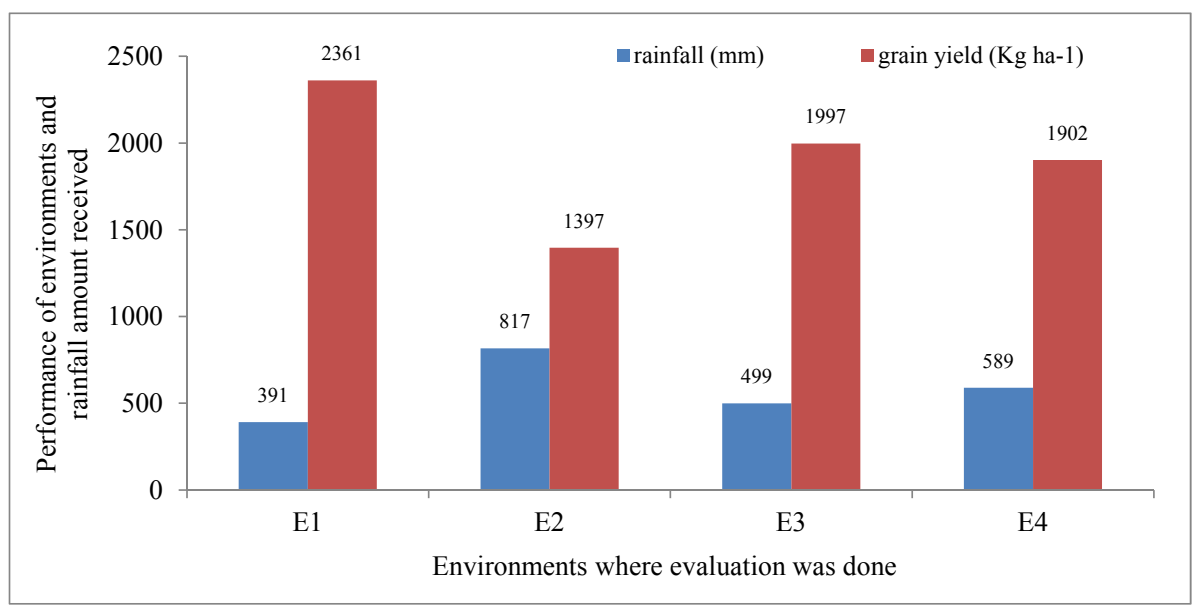

Figure 1. Total amount of rainfall received during the evaluation period and performance of environments Source for rainfall data: Department of Meteorology, Ministry of Water and Environment, Uganda.



Figure 2. Performance of environments in terms of rust severity

\subsection{Assessing GEI Using GGE Biplot Analysis}

Figure 3 shows that E1 was the ideal environment while E3 was desirable for grain yield. Both environments were positively correlated and associated with high grain yield and grouped as one mega environment (Figure 4); implying the two environments had similar discriminating ability and so either can be used for selecting best performers with minimal loss of information (Yan \& Kang, 2003). E2 was not important in discriminating genotypes due to being at the origin while $\mathrm{E} 4$ was the most unstable for grain yield. The genotype $6 \times 8$ (Shibe $\times$ CIVT9206; grain yield $=2387 \mathrm{~kg} \mathrm{ha}^{-1}$, rust severity $=24.36 \%$ ) was the most ideal for grain yield while 
$1 \times 14\left(\right.$ ICMV3771 $\times$ SDMV96053; grain yield $=2355 \mathrm{~kg} \mathrm{ha}^{-1}$, rust severity $\left.=24.63 \%\right)$ was the winner in the E1E3 mega environment. Figure 4 also indicates genotypes $6 \times 7$ (Shibe $\times$ Exbornu), $6 \times 8$ (Shibe $\times$ CIVT9206), $1 \times 14$ $($ ICMV3771 $\times$ SDMV96053) and $5 \times 8$ (SDMV94001 $\times$ CIVT9206) performing averagely the same in the E1E3 mega environment while $6 \times 9$ (Shibe $\times$ GGB8735; grain yield $=2371 \mathrm{~kg} \mathrm{ha}^{-1}$, rust severity $=23.85 \%$ ) and $2 \times 15$ (Manganara $\times$ Sosank; grain yield $=2169 \mathrm{~kg} \mathrm{ha}^{-1}$, rust severity $=20.68 \%$ ) won in the low yield unstable E4 mega environment and thus the source of crossover GEI effect. The high yielding genotypes were also moderately susceptible to rust. The stable and high yielding genotypes were different from those resistant to rust. The discrimination polygon (Figure 5) is a view for the environments for rust resistance. E2 and E4 were extremely discriminatory for rust resistance. The two environments were in this case the sources of crossover GEI relative to E1 and E3. The genotypes in mega environment E4 were associated with relatively high rust resistance and they included; $6 \times 11$ (Shibe $\times$ ICMV221white; grain yield $=2030 \mathrm{~kg} \mathrm{ha}^{-1}$, rust severity $=27.58 \%$ ), 6×10 $\left(\right.$ Shibe $\times$ ICMV221; grain yield $=2506 \mathrm{~kg} \mathrm{ha}^{-1}$, rust severity $\left.=24.76 \%\right), 6 \times 7$ (Shibe $\times$ Exbornu; grain yield $=2149$ $\mathrm{kg} \mathrm{ha}^{-1}$, rust severity $\left.=22.39 \%\right), 6 \times 8\left(\right.$ Shibe $\times$ CIVT9206; grain yield $=2387 \mathrm{~kg} \mathrm{ha}^{-1}$, rust severity $\left.=24.36 \%\right)$. Generally the genotypes associated with high rust resistance were also highly unstable in terms of grain yield and associated with the unstable environments E2 and E4 (Figure 6). These observations emphasize the importance of GEI and adopting selection for specific environments. In many pearl millet studies the GGE biplot has also been used to identify pearl millet mega environments to reduce number of test environments (Gupta et al., 2013; Ishaq et al., 2014). Mashiri et al. (2014) adopted the GGE biplot technique to estimate environmental effects for days to flowering, plant height and physiological maturity (Bashir et al., 2014). In addition, Gebre (2014) and Mustapha and Bakari (2014) used the GGE biplot analysis to identify stable genotypes with high grain yield while Bashir et al. (2014) identified best performers for grain yield. Thus, the practicality in using the GGE biplot merits its use in selecting for stability and adaptability of genotypes for grain yield and other yield-related traits.

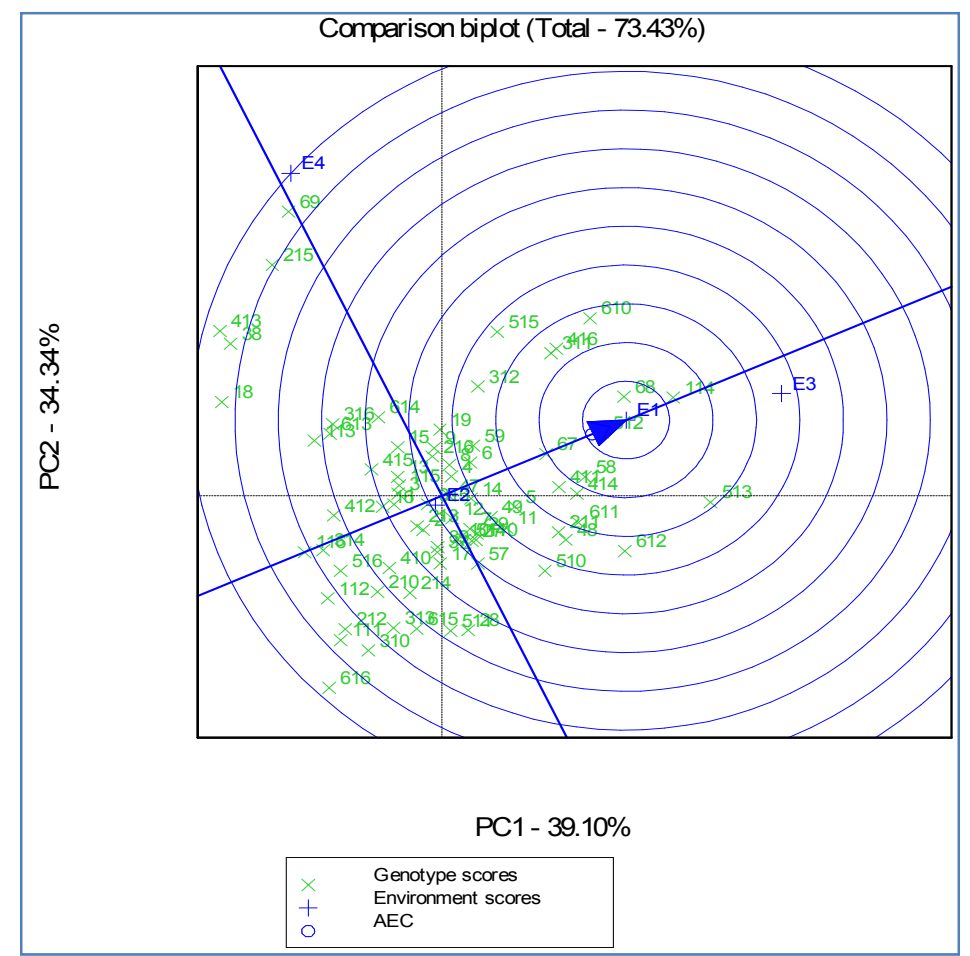

Figure 3. Ranking genotypes based on both means and stability for grain yield across environments 


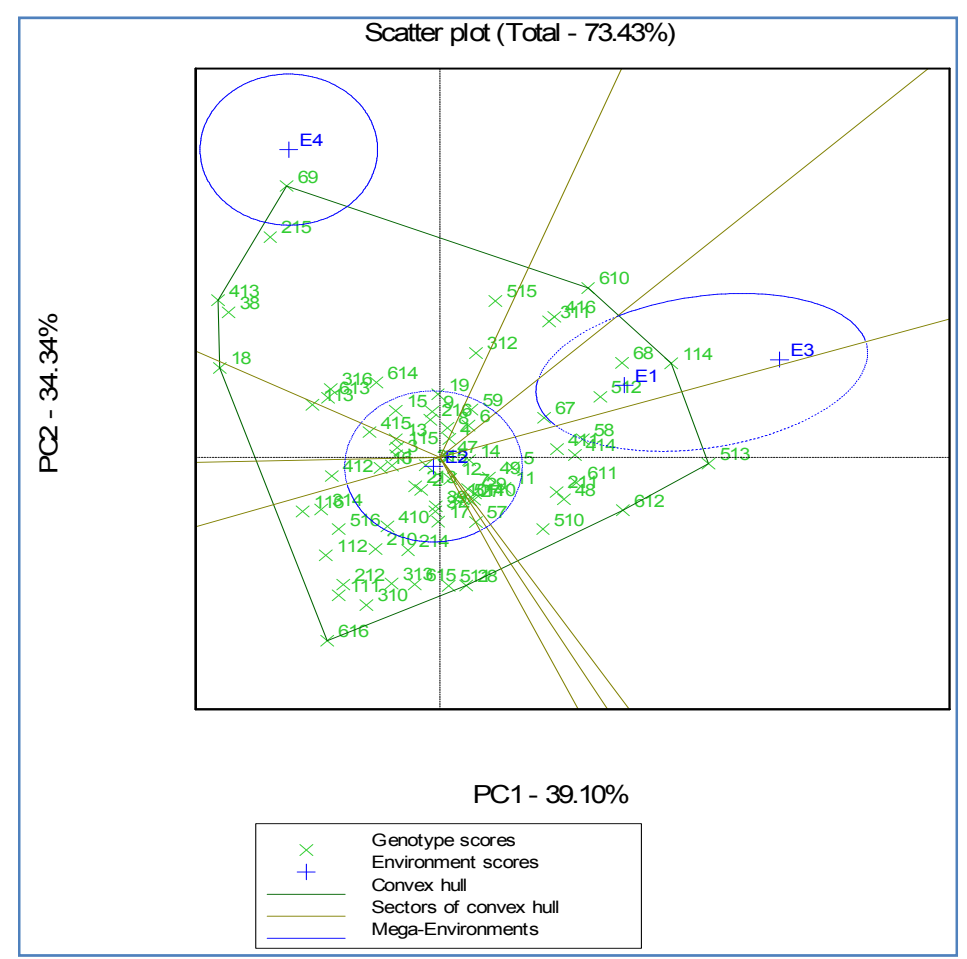

Figure 4. 'Which won where' with mega environments for grain yield

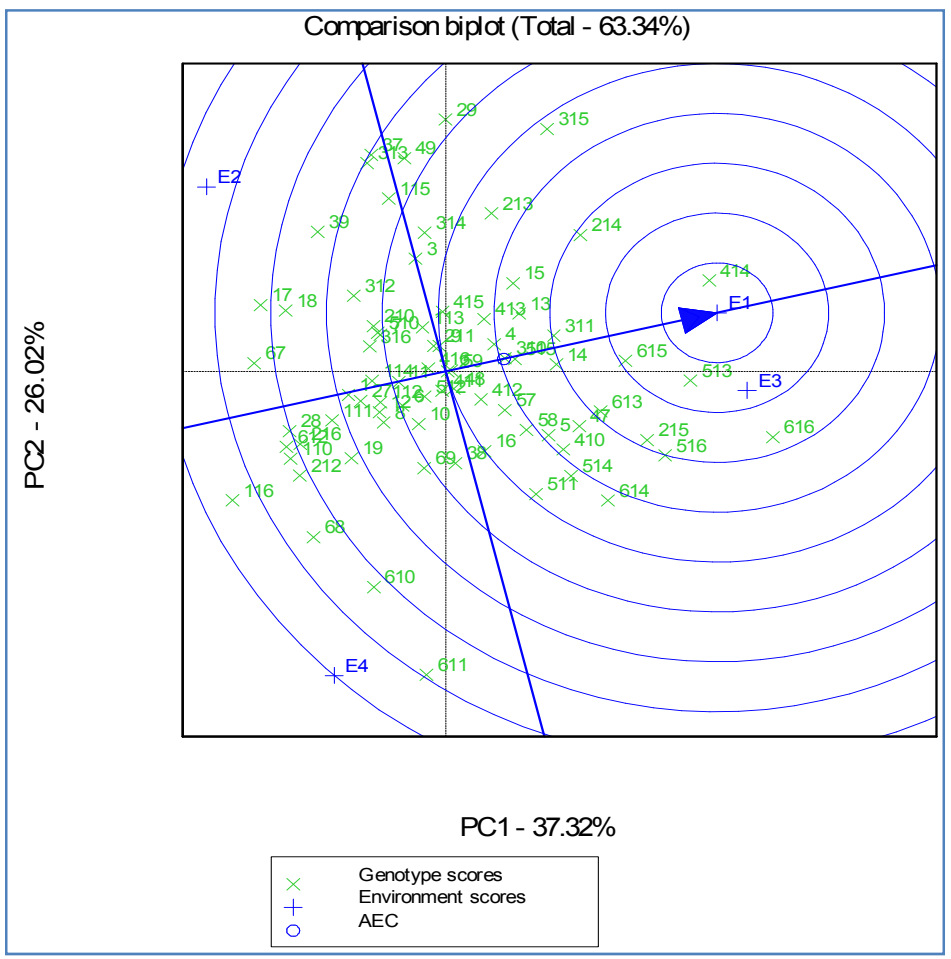

Figure 5. Association between environments for rust severity 


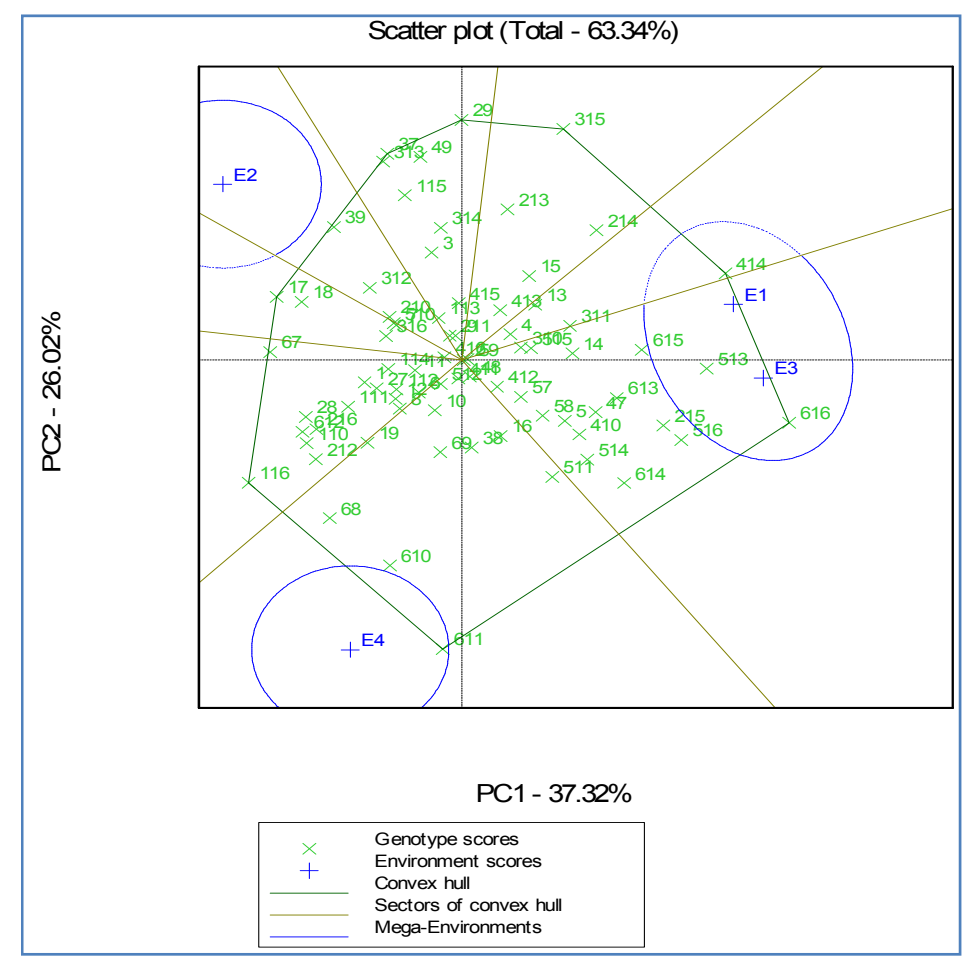

Figure 6. 'Which won where' with mega environments for rust severity

\section{Conclusion}

The study focused on establishing the genotype by environment interaction effect, characterising environments and genotypes. The ANOVA results showed that the effects of environments, genotypes and genotype $\mathrm{x}$ environment interaction (GEI) were important in trait expression and performance of genotypes. In addition, it was observed that amount of rainfall received at both vegetative and post-anthesis phases had an effect on grain yield and disease severity. Finally, the GGE biplot was useful in concisely characterising the environments and the genotypes. It characterised the environments in terms of stability and productivity. This resulted in grouping of mega environments with E2 and E4 being ideal for rust discrimination while E1E3 was the best for grain yield; implying that environment-specific selection should be adopted.

\section{References}

Bashir, E. M. A., Ali, A. M., Adam-Ali, M., Ismail, M. I., Parzies, H. K., \& Haussmann, B. I. G. (2014). Patterns of pearl millet genotype-by-environment interaction for yield performance and grain iron $(\mathrm{Fe})$ and zinc $(\mathrm{Zn})$ concentrations in Sudan. Field Crops Research, 166, 82-91. https://doi.org/10.1016/j.fcr.2014.06.007

CIMMYT. (2014). Integrated Breeding Platform's Breeding Management System version 3.0 (IBP-BMS). Integrated Breeding Platform, CIMMYT, Veracruz, Mexico.

Cooper, M., \& DeLacy, I. H. (1994). Relationships among analytical methods used to study genotypic variation and genotype-by-environment interaction in plant breeding multi-environment experiments. Theoretical and Applied Genetics, 88(5), 561-572. https://doi.org/10.1007/BF01240919

Crossa, J. (1990). Statistical analysis of multilocational trials. Advances in Agronomy, 44, 55-85. https://doi.org/10.1016/S0065-2113(08)60818-4

Directorate of Plant Protection (DPP). (2011). Pearl millet production guide. DPP, South Africa.

Ezeaku, I. E., Angarawai, I. I., Aladele, S. E., \& Mohammed, S. G. (2014). Genotype by environment interactions and phenotypic stability analysis for yield and yield components in parental lines of pearl millet (Pennisetum glaucum [L.] R. Br). African Journal of Agricultural Research, 9(37), 2827-2833. https://doi.org/10.5897/ AJAR2014.8930

Gebre, W. (2014). Evaluation of pearl millet (Pennisetum glaucum L.) genotypes for yield and yield stability in South Omo and West Hararghe. Journal of Biology, Agriculture and Healthcare, 4(8), 99-121. 
Gupta, S. C., \& Ndoye, A. T. (1991). Yield stability analysis of promising pearl millet genotypes in Senegal. Maydica, 36, 83-86.

Gupta, S. K., Rathore, A., Yadav, O. P., Rai, K. N., Khairwal, I. S., Rajpurohit, B. S., \& Das, R. R. (2013). Identifying mega-environments and essential test locations for pearl millet cultivar selection in India. Crop Science, 53(6), 2444-2453. https://doi.org/10.2135/cropsci2013.01.0053

Haussmann, B. I. G., Rattunde, H. F. W., Weltzien-Rattunde, E., Traoré, P. S. C., vom Brocke, K., \& Parzies, H. K. (2012). Breeding strategies for adaptation of pearl millet and sorghum to climate variability and change in West Africa. Journal of Agronomy and Crop Science, 198, 327-339. https://doi.org/10.1111/j.1439-037X. 2012.00526.x

IBPGR \& ICRISAT. (1993). Descriptors for Pearl Millet (Pennisetum glaucum (L.) R. Br.). IBPGR \& ICRISAT, Rome. Retrieved from http://www.bioversityinternational.org/e-library/publications/detail/descriptors-for-p earl-millet-empennisetum-glaucumem-l-r-br

IFAD. (1999). Farmer participatory testing of technologies to increase sorghum and pearl millet production in the Sahel. Retrieved from http://www.ifad.org/grants

Ishaq, J., \& Meseka, S. (2014). Genetic Stability of Grain Yield and principal component analysis in pearl millet (Pennisetum glaucum L.). Greener Journal of Plant Breeding and Crop Science, 2(4), 88-92.

Khairwal, I. S., Rai, K. N., Diwakar, D., Sharma, Y. K., Rajpurohit, B. S., Nirwan, B., \& Bhattacharjee, R. (2007). Pearl millet: Crop management and seed production manual (p. 104). International Crops Research Institute for the Semi-Arid Tropics, Patancheru 502 324, Andhra Pradesh, India.

Lubadde, G., Tongoona, P., Derera, J., \& Sibiya, J. (2014). Major pearl millet diseases and their effects on on-farm grain yield in Uganda. African Journal of Agricultural Research, 9(39), 2911-2918. https://doi.org/10.5897/AJAR2013.7208

Mashiri, C. E., Chikerema, P., Murewi, C. T. F., Gonzo, L., Maposa, S., Pfupajena, M. H., ... Sisito, G. (2014). Estimating environmental effects using the agronomic traits of pearl millet varieties by means of the biplot technique. International Journal of Advanced Scientific and Technical Research, 2(4), 72-91.

Matus-Cadiz, M. A., Hucl, P., Peron, C. E., \& Tyler, R. T. (2003). Genotype $\times$ environment interaction for grain colour in hard white spring wheat. Crop Science, 43, 219-226. https://doi.org/10.2135/cropsci2003.2190

Misra, R. C., Das, S., \& Patnaik, M. C. (2010). AMMI analysis of stability and adaptability of late duration finger millet (Eleusine coracana) genotypes. World Journal of Agricultural Sciences, 6(6), 664-669.

Mustapha, M., \& Bakari, H. R. (2014). Statistical evaluation of genotype by environment interactions for grain yield in millet (Pennisetum glaucum (L.) R. Br). International Journal of Engineering and Science, 3(9), 7-16.

Payne, R. W., Murray, D. A., Harding, S. A., Baird, D. B., \& Souter, D. M. (2012). GenStat for windows 14th edition introduction. VSN International, Hemel Hempstead.

Singh, S. D. (1990). Sources of resistance to downy mildew and rust in pearl millet. Plant Disease, 74, 871-874. https://doi.org/10.1094/PD-74-0871

Thakur, R. P., Rajan, S., \& Rao, V. P. (2011). Screening techniques for pearl millet diseases. Information Bulletin No. 89 (p. 56). Patancheru 502 324, Andhra Pradesh, India: International Crops Research Institute for the Semi-Arid Tropics.

Tooley, P. W., \& Grau, C. R. (1984). Field characterisation of rate reducing resistance to Phytophthora megasperma f.sp. glycinea in soybean. Phytopathology, 74, 1201-1208. https://doi.org/10.1094/ Phyto-74-1201

Vadez, V., Hash, T., Bidinger, F. R., \& Kholova, J. (2012). Phenotyping pearl millet for adaptation to drought. Frontiers of Physiology, 3, 1-12. https://doi.org/10.3389/fphys.2012.00386

Yan, W., \& Kang, M. S. (2003). GGE Biplot Analysis: A graphical tool for breeders, geneticists, and agronomists. CRC Press, Boca Raton, FL.

Yan, W., \& Racjan, I. (2002). Biplot analysis of test environments and trait relations of soybean in Ontario. Crop Science, 42, 11-20. https://doi.org/10.2135/cropsci2002.0011

Yan, W., Kang, M. S., Ma, B., Woods, S., \& Cornelius, P. L. (2007). GGE Biplot vs. AMMI Analysis of genotype-by-environment data. Crop Science, 47(2), 643-653. https://doi.org/10.2135/cropsci2006.06.0374 


\section{Copyrights}

Copyright for this article is retained by the author(s), with first publication rights granted to the journal.

This is an open-access article distributed under the terms and conditions of the Creative Commons Attribution license (http://creativecommons.org/licenses/by/4.0/). 